May 2012

\title{
Using Organization Theory to Explore the Changing Role of Medical Libraries
}

Kathy J. Fatkin

Emporia State University, fatkin.kathy1@gmail.com

Follow this and additional works at: https://scholarworks.sjsu.edu/ischoolsrj

Part of the Library and Information Science Commons

Acknowledgements

Thank you to Mirah Dow for her help and encouragement.

\section{Recommended Citation}

Fatkin, K. J. (2012). Using Organization Theory to Explore the Changing Role of Medical Libraries. School of Information Student Research Journal, 2(1). https://doi.org/10.31979/2575-2499.020105 Retrieved from https://scholarworks.sjsu.edu/ischoolsrj/vol2/iss1/5

This article is brought to you by the open access Journals at SJSU ScholarWorks. It has been accepted for inclusion in School of Information Student Research Journal by an authorized administrator of SJSU ScholarWorks. For more information, please contact scholarworks@sjsu.edu. 


\title{
Using Organization Theory to Explore the Changing Role of Medical Libraries
}

\author{
Abstract \\ This historical research review uses organization theory to describe and interpret the evolution of \\ American hospitals, medical libraries, and the role of the professional librarian. Various organization \\ theories are applied to explain changes in hospitals and medical libraries over time. The interaction \\ between the organization and the environment as described in organization theory shaped the emergence \\ of today's information services. For readers unfamiliar with health sciences libraries, the study will provide \\ a glimpse into the social forces that framed the development of this type of special library.

\section{Keywords} \\ Organization theory, hospitals, medical library services, evidence-base practice

\section{Acknowledgements} \\ Thank you to Mirah Dow for her help and encouragement.

\section{About Author} \\ Kathy J. Fatkin is a doctoral student at Emporia State University in Emporia, Kansas. She works at Eastern \\ Idaho Regional Medical Center as a solo librarian in the medical library and she is also a registered nurse. \\ Her research interests include how nurses use information to improve patient care and how the health \\ science librarian can better serve nurses in acute care settings.
}


Using Organization Theory to Explore the Changing Role of Medical Libraries

Some hospitals are closing their medical libraries while others are expanding their medical libraries with new information services. Information is an essential resource for quality healthcare and ranges from patient-specific data to diagnostic test results. Medical libraries provide hospital staff with knowledge-based information services to support patient care. Can organization theory explain the changes in United States (U.S.) medical libraries and the services professional librarians provide to the hospital staff?

This historical research study applies organization theory to describe how hospitals, medical libraries, and other health sciences librarians first appeared in American society, and how they changed and developed into today's high-tech organizations and professionals with a focus on cost-effective information services.

Organization theory developed into a specialized field after the translation of Max Weber's work on bureaucracy into English in 1946 (Scott \& Davis, 2007). The theory can focus our view on how the healthcare system, hospitals, and, in particular, medical libraries, emerged in the U.S.; these institutions arose in response to changes in the environment, with new technologies, developing social and physical structures, and power struggles among their stakeholders.

\section{Organization Theory}

Organization theory is multidisciplinary, with sociologists, economists, political scientists, biologists, psychologists, and engineers contributing to the theory. Modernists, symbolic-interpretive, and postmodern scholars within these fields add to the field of organization theory (Hatch \& Cunliffe, 2006). Each of these disciplines has developed a perspective of reality, influenced by the discipline's theories about what is knowable (ontology) and how we know it (epistemology). The various disciplines' perspectives reflect different assumptions about the nature of an organization (Hatch \& Cunliffe, 2006).

The modernists' ontology is objectivism. Modernists accept an external reality that exists independently from our knowledge. Modernists believe that knowledge is discovered by using scientific methods of observation with valid and reliable measurements that allow us to test our understanding of the world. The modernist sees organizations as real entities operating in a real world where it is possible to test methods and techniques to improve effectiveness (Hatch \& Cunliffe, 2006). Symbolic-interpretive researchers believe instead in an ontology of subjectivism, which suggests that nothing exists apart from our awareness of it. Symbolic-interpretive theorists believe that knowledge is constructed and can only be understood from the point of view of the individuals directly involved. 
Accordingly, the "truth" shifts and changes through time as societies change. This group understands organizations to be constructed and reconstructed by their members, who apply meaning to the symbols and actions of people within the organization. The organization is a humanly-produced reality that is understandable as a social product (Berger \& Luckmann, 1966). Finally, postmodern theorists' ontology is that the world appears to us through language and discourse. They describe knowledge as the accepted interpretation of meaning derived from individuals with power. Post-modern theorists see organization as texts that can be deconstructed and rewritten to reveal the viewpoints of those who are oppressed (Hatch \& Cunliffe, 2006).

These various beliefs about knowledge and the nature of organizations provide useful lenses for considering the evolution of hospitals, medical libraries, and health sciences librarians in American society. Using multiple viewpoints for describing the changes in healthcare over time provides a better description of the various forces that shape the decisions stakeholders are now making about information services for today's hospitals.

All organization theorists conceptualize organizations as a part of a larger environment that supplies resources and absorbs goods and services. Within the organization, there are social structures that order activity, cultures that produce meaning, physical structures that support and constrain the organization's activity, and technology that produce goods and services (Hatch \& Cunliffe, 2006). Hatch and Cunliffe (2006) describe these internal organizational concepts as interconnected and responsive to each other and to the external environment.

Modern organization theorists' overarching goal is to predict and control organizations. Symbolic-interpretive organization theorists instead seek to understand the meaning of the socially constructed organization. Postmodern organization theorists seek to expose the practices of those with power and encourage self-determination for those who have not found their voices. Each of these subsets of organization theory helps to examine and evaluate how American hospitals, medical librarians, and health sciences librarians have changed over time.

\section{Evolution of American Hospitals}

Hospitals are complex organizations with a rich history. Early American hospitals were charitable organizations, established by religious and ethnic groups to tend to the sick. Before the 1900s, hospitals were almshouses that served the sick sailor and other travelers who fell ill, or the poor who had no one to care for them (Starr, 1982). Families cared for their sick in their own homes; "those who had homes did not use hospitals" (Griffin \& White, 2002, p. 5). With industrialization, work moved outside the home and it became difficult for 
families to care for the sick. City flats and apartments had no space for a sickroom (Starr, 1982). The growth in hospital care was a response that fit the needs of the newly industrialized city. Organization theory considers how the environment influences organizational development. Aldrich (1979), a modernist organization theorist, studies the effect of the environment on organizations. His population ecology theory describes how external forces and the resources available in the environment create niches for the growth of organizations such as hospitals.

Wealthy industrialists and other donors funded early hospitals (from roughly 1760 to 1860) and they served on their boards of directors. These benefactors used hospital philanthropy as a way to convert their wealth into status; serving on the hospital board allowed donors a certain amount of power and influence (Starr, 1982). However, donations did not cover all the costs of hospitals, so the wealthiest patients were charged a premium price for private rooms. Other patients were cared for together in wards, either as paying patients or as charity patients. The social stigma associated with being in the hospital was eliminated when hospitals began to charge for services. During the great depression (1930s), the highest income patients had the highest hospital admission rates (Andersen, Rice \& Kominski, 2001). The meaning of being a patient in the hospital changed from an association with poverty to an association with wealth. Hospitals became prominent institutions in their communities by scripting their roles and serving those with power. A different type of organization theory can help explain this change.

Weick, Sutcliffe and Obstfeld's (2005) symbolic-interpretive organization theory model of sensemaking describes how scripting a story makes an organization appear orderly and more understandable. The hospital story was revised from a charity that served only the poor to an organization that provided healthcare for all people. The wealthy donor and the private room patient dominated the discourse of the hospital, using postmodern theory as described by Jean-Francois Lyotard (Mitcham, 2005). These views of organization theory all apply to the transformation of the hospital in American society.

With the development of asepsis and anesthesia after the Civil War (18671930), surgery became safer and hospitals began to offer not only care for the sick, but the possibility of a cure. Growth in surgery "provided the basis for expansion and profit in hospital care" (Starr, 1982, p. 157) and the hospital came to be seen as the physician's workshop. Hospitals had the market advantage of providing facilities that could be used by many surgeons, without the necessity of organizing the physicians themselves (Griffith \& White, 2002). The success of surgical technology created piecework in hospital care, as surgeons handed off the care of post-surgical patients to nurses for recovery. Curing became the domain of the doctor, while caring became the duty of the nurse (Ehrenreich \& English, 
1973). Organization theory is useful in examining these changes in the hospital organization.

Woodward (as cited in Hatch \& Cunliffe, 2006, p. 146) was an early modernist organization theorist who linked production with technology; she looked at how mechanical technologies determined how work was performed. Depending on available technology, work was accomplished in small batches by a single worker or divided into pieces to hand off to other workers (Hatch \& Cunliffe, 2006). Surgical technology changed the work that was performed in the hospital and the organization responded as predicted by modernist organization theory.

Further growth in technology in healthcare after World War II (19461960) created the need for administrators with business skills to lead the hospital (Starr, 1982). The hospital administration required physicians utilizing the hospital to meet certain standards for quality of care (Hader, 2011). Again, organization theory can help explain the unique division of decision-making in the hospital setting; where physicians direct the individual patient's care and administrators direct the hospital as an organization. Bourdieu's postmodern concept of organization structure (as cited in Hatch \& Cunliffe, 2006, p. 124) as field (social space) and habitus (social position) is useful in describing the dual distribution of power in the hospital, split between physicians and administrators. According to Bourdieu, individuals with expert knowledge and skills have capital within the organizations' hierarchy and can exert power. Habitus provides the social hierarchy that determines the way the capital is controlled and determines the rules for exerting power in organizational relationships. In healthcare, the physician's power comes from the social capital associated with medicine, while administrators have the social capital of business knowledge. Competition and struggle between these social forces modified the structure of the hospital as an organization.

\section{Evolution of American Medical Libraries}

As the surgeon rose in prominence (1930-1960), the American College of Surgeons (ACS) began to set standards for hospitals in the U.S., including standards for libraries and librarians. In 1934, the ACS published a list of books recommended for the hospital library and described the need for a qualified librarian (Wolfgram, 1985). These earliest hospital libraries were collections of pooled medical texts that served the hospital's interns, physicians, and surgeons. The hospital was focused on improving the knowledge and skills of the doctor within the organization (Starr, 1982), with the hospital library serving as a storehouse of knowledge for doctors (Holst, 1991). With these libraries in place, a tradition of service to the medical staff was established (Holst, 1991). 
After World War II, the ACS could no longer keep pace with the need to monitor hospitals. The ACS and other groups formed the Joint Commission on Accreditation of Hospitals, (now called simply the Joint Commission (JC)) to survey hospitals for quality. When the JC released its hospital standards in the Accreditation Manual for Hospitals, the JC required a medical library staffed with a competent librarian to meet the information needs of the medical staff (Bradley, 1983). Organization theory may be used to explain the need for the health science library in the hospital after the war. Jay Galbraith's modernist organization theory of information processing and technology explains that as technology increases in complexity more communication is required to mediate the relationships between structure, technology, and the environment (as cited in Hatch \& Cunliffe, 2006, p. 167). The period after World War II included rapid growth in government funding for scientific research, including medical research (Starr, 1982). The medical librarian played an adaptive role for dissemination of information from the growing body of medical research to physicians.

In the 1960s, legislation enabled the development of a network of regional medical libraries. The Medical Library Assistance Act (MLAA) was passed to: (a) aid health science libraries to develop services and resources, and (b) to promote a national system of regional health sciences libraries accessible by all health professionals. The MLAA authorized the National Library of Medicine (NLM) to provide funds to accomplish these goals through grants to libraries. Regional resource libraries were established from existing medical libraries. The NLM coordinated the funding at the national level, but the regional resource libraries determined the programs to meet local needs. All the NLM regions relied on hospital librarians to act as intermediaries between health professionals and the information resources provided by local, regional, and national libraries. At that time, the number of hospital libraries increased from a core group of about 1,700 to about 2,000 hospital libraries, with the growth experienced predominantly among hospitals with 500 beds or fewer (Thibodeau \& Funk, 2009). Funding from the Social Security Act for research and the requirement of the JC for hospital libraries spurred the creation of new hospital libraries (Holst, 1991). Organization theory explains how the impact of outside forces such as increased funding for research changed the hospital.

Laurence and Lorsch (1986) use modernist organization theory to describe how organizations respond to changes in their environment. The structure of the medical library changed as hospital staff requested more research-based information. The technology of information transfer shifted from books to journals. The librarians' role also changed as resource sharing became necessary to meet the information needs of the organization.

In the 1970s, medical libraries changed again with the advent of the Medical Literature Analysis and Retrieval System. At the system's creation, a 
few large academic and regional medical libraries had remote access to the system through "dumb" terminals. Shortly thereafter, the system was renamed MEDLINE. By 1978, over 900 institutions had access to the MEDLINE database (Atlas, 2000). NLM regional staff trained medical librarians on how to use the required Boolean logic, controlled vocabularies, and command language needed to navigate the system. MEDLINE charged connection fees along with per character charges, so the librarian searcher would plan a literature search strategy carefully before typing into the database to control search costs. Librarians were early adopters of this new technology.

Again, organization theory helps explain the impact of a new technology on the medical library. According to Schein (2010), a symbolic-interpretive researcher, every organization has a group that represents the technology used in an organization. This is the engineering subculture, and with the creation of MEDLINE, librarians became more like engineers by interacting with the technology that changed access to journal information resources.

By the 1980s, mediated MEDLINE searches had reached a volume of two million searches a year (Atlas, 2000). Medical library staffing levels increased to match the demand, and librarians enjoyed the social capital that comes from possessing expert skills and special knowledge. Technology in the organization improved access to information via intermediaries and the hospital responded with fully staffed medical libraries. However, mediated searching was becoming too much of a constraint in connecting information with healthcare providers. Organizations operate within various constraints and organization theory addresses how constraints shape the organization. Simon (1973), a modernist, evaluated the organization as a social system. He found that constraints motivate participants to conform, but too much constraint limits the ability of the organization to respond to the environment.

In the 1990s, as personal computers were becoming common in the workplace, the NLM developed a personal computer interface for health professionals to do their own searching. Vice President Al Gore announced in 1997 that access to the PubMed version of the MEDLINE database would be offered free of charge on the World Wide Web. As a result, end-user searching became widespread and mediated searching decreased significantly (Atlas, 2000). The change in technology with personal computers produced the need for instruction in the use of online library resources and services. Many librarians added end-user instruction to their library services after the removal of the cost constraints to database searching.

Another modernist organization theory is useful to examine the adoption of technology in the hospital. Organization theorists Katz and Kahn apply open systems theory (as cited in Hatch \& Cunliffe, 2006, p. 121) to explain how organizations adapt to changes in technology with support activities. Work is 
distributed and integrated in the organization differently due to technological advancement.

Also in the 1990s, healthcare expenditures rose rapidly. The federal government began work on cost containment regulations to place greater financial accountability on hospitals. In a change in policy, Medicare no longer considered library services as a reimbursable expense and dropped its requirement of a medical librarian for hospital payments. The JC changed its accreditation requirements, allowing an onsite library or a cooperative arrangement for library services to provide hospital information services. More hospitals began to use contractors for their library services and medical libraries downsized or were closed (Thibodeau \& Funk, 2009). Hospital library layoffs occurred as some hospitals reorganized and replaced librarians with clerical staff (Gilbert, 1991).

The hospital response to financial incentives is understandable by applying another modernist organization theory. Hospital buildings are designed for providing healthcare services; the medical library space is designed for both collecting and disseminating knowledge-based documents and services. Investments in buildings, equipment, and staff create structural inertia in organization theory, as described by Hannan and Freeman (1984). Hospitals are not particularly flexible due to this structural inertia, but they do respond to their environment. When knowledge-based documents are not required within the physical building, library space can be reallocated to another healthcare service.

\section{Evidence-Based Practice in Healthcare}

Even while some medical libraries were closing (1990 to present), other medical libraries were able to increase library services to support evidence-based practice. Rising healthcare costs and a need for quality improvement created a climate for change in healthcare delivery (Davis, 2010). The concept of evidence-based practice in healthcare began in the 1990s with Archie Cochrane, an epidemiologist who called for a system to produce research summaries to sort out the claims for various therapies in medicine (Jennings \& Loan, 2001). His work inspired the creation of the Cochrane Library and the Cochrane Database of Systematic Reviews (Cleary-Holdforth \& Leufer, 2008) which explicitly appraises evidence for interventions. Evidence-based practice uses the best scientific evidence, along with clinical experience and patient values and preferences, to guide patient care. It is a change from healthcare based on expert opinion (Davis, 2010). Medical librarians responded to this change by developing specific search techniques to locate evidence for practice (Klem \& Weiss, 2005). Again, organization theory explains the librarians' adaptation to changes in the hospital environment. Weick (as cited in Hatch \& Cunliffe, 2006, p. 127) uses the 
symbolic-interpretive theory of organizational improvisation to describe how routines change in response to the needs of the organization.

By the late 1990s, evidence-based guidelines were being published to direct patient care. The healthcare professional was expected to select treatment based on current research-based guidelines, not personal preferences. Government payers and insurance providers were pushing for more standardized healthcare which did not vary illogically from region to region. Evidence-based guidelines reduced mortality in conditions such as heart attacks (Torpy, Lynm \& Glass, 2009). This push for care based on research-based evidence and guidelines created new conflicts in the hospital organization. Modernist organization theorist Edgar Schein (2010) studied organizational subcultures and described how conflicting subcultures can reduce effectiveness in an organization.

A Veteran's Affairs hospital looked at hospital subcultures and the use of evidence-based guidelines. The researchers found the executive culture (i.e., hospital administrators and the chief of staff) described cost, market share, and efficiency in their statements about practice guidelines. The operator culture (i.e., staff physicians and nurses) described stress and time pressure, and made statements that the guidelines did not help. The engineering culture (i.e., physicians, nurses, and computer support staff who designed the guidelines) made statements about variability, capacity, and quality of the guidelines. As the researchers expected, the different cultures produced barriers to implementing evidence-based care (Smith, Francovich, \& Gieselman, 2000). Organization theory explains how a strong leader with a commitment to safety and quality healthcare can unite the subcultures by creating a shared goal (Schein, 2010).

A supportive culture must be present to provide evidence-based care (Reavy \& Tavernier, 2008). The "magnet designation" from the American Nurses Credentialing Center provides recognition that a hospital has a culture of evidence-based practice and a professional practice environment attractive to nurses and patients (Luzinski, 2011). Magnet programs encourage collaboration with librarians using multidisciplinary teams to gather and evaluate evidence for practice. As nurses move from their traditional patterns of care to evidence-based care, they deal with multiple barriers within the hospital organization. The complexity of finding and evaluating evidence for nursing care is challenging. Organizations respond to task complexity and interdependence with new structural relationships (Scott \& Davis, 2007). Librarians have begun to promote services to nurses, and nurses have begun asking for librarian-mediated searches as they confront complex clinical questions that require expert searching skills (Holst et al., 2009). Hospital librarians support nursing professionals by finding and demystifying research studies (Rourke, 2007) and by overcoming the barriers faced by busy staff trying to locate the best evidence (Holst et al., 2009; Strickland \& O'Leary-Kelley, 2009). 
Evidence-based healthcare is a valuable tool in reducing the gap between what we know from research and what we do in practice. This research into practice gap has been recognized in all healthcare disciplines. Public policy can alter organizations as they respond to political pressure (Scott \& Davis, 2007) to improve healthcare outcomes. One response to this pressure is the creation of the "informationist" role in some hospitals; an informationist is a team member who translates, synthesizes, and contextualizes research for others (Davidoff \& Florance, 2000; Grefsheim et al., 2010). Another development in information services is the increasing number of knowledge brokers, information professionals who are able to link users and creators of knowledge to produce desired changes in healthcare providers (Funk, 1998; Thompson, Estabrooks, \& Degner, 2006). The medical librarian, who is comfortable with reading research and translating findings for others, can easily fulfill the role of informationist or knowledge broker. Outside forces are once again reshaping the responsibilities of the medical librarian.

\section{Conclusion and Recommendations for Further Research}

The U.S. healthcare system emerged in response to forces identified in organization theory. The medical library's transformation from storehouse of knowledge to part of a network of information can be explained in terms of the major concepts of organization theory. Social structures and technology influenced how the librarian aligns the information needs of the hospital and its staff to the community it serves. Modernist theorists provide the framework for both the growth and decline of hospitals and medical libraries as technology has evolved. Symbolic-interpretive theorists explain how we recreate our roles in organizations and redefine library work in response to social systems. Postmodern theorists identify how power influences organizations and how professional librarians' status has changed over time.

Additional research questions about the differences between clinical librarians, knowledge brokers, and informationists need answers. Historical research cannot identify the forces yet to appear. New research questions about the importance of the library as place are emerging as librarians move to support specific units and information becomes mobile through the use of handheld devices. Organization theory is an excellent framework to use as librarians look at these trends and consider how the past has influenced today's organization of the hospital and medical library. 


\section{References}

Aldrich, H. E. (1979). Organizations and environments. Englewood Cliffs, NJ: Prentice-Hall.

Andersen, R. M., Rice, T. H., \& Kominski, G. F. (2001). Changing the U.S. health care system: Key issues in health services policy and management. (2nd ed.). San Francisco, CA: Jossey-Bass.

Atlas, M. C. (2000). The rise and fall of the medical mediated searcher. Bulletin of the Medical Library Association, 88(1), 26-35.

Berger, P. L., \& Luckmann, T. (1966). The social construction of reality: A treatise on the sociology of knowledge. Garden City, NY: Anchor Books.

Bradley, J. (1983). Hospital library management. Chicago, IL: Medical Library Association.

Cleary-Holdforth, J., \& Leufer, T. (2008). Essential elements in developing evidence-based practice. Nursing Standard, 23(2), 42-46.

Davidoff, F., \& Florance, V. (2000). The informationist: A new health profession? Annals of Internal Medicine, 132(12), 996-998.

Davis, B. J. (2010). Improving healthcare outcomes through EBM. Health Management Technology, 31(10), 24-5.

Ehrenreich, B., \& English, D. (1973). Witches, midwives and nurses: A history of women healers. New York, NY: The Feminist Press.

Funk, C. J. (1998). Evolving roles of life and health sciences librarians for the twenty-first century. Bulletin of the Medical Library Association, 86(3), 380-384.

Gilbert, C. M. (1991). Challenges in healthcare information transfer: The role of hospital libraries. Bulletin of the Medical Library Association, 79(4), 405408.

Grefsheim, S. F., Whitmore, S. C., Rapp, B. A., Rankin, J. A., Robison, R. R., \& Canto, C. C. (2010). The informationist: Building evidence for an 
emerging health profession. Journal of the Medical Library Association, 98(2), 147-156. doi:10.3163/1536-5050.98.2.007

Griffith, J. R., \& White, K. R. (2002). The well-managed healthcare organization. (5th ed.). Chicago, IL: Health Administration Press.

Hader, R. (2011). Docs: Partners or customers? Nursing Management, 42(3), 6.

Hannan, M. T., \& Freeman, J. (1984). Structural inertia and organizational change. American Sociological Review, 49(2), 149-164.

Hatch, M. J., \& Cunliffe, A. L. (2006). Organization theory: Modern, symbolic, and postmodern perspectives (2nd ed.). New York, NY: Oxford University Press.

Holst, R. (1991). Hospital libraries in perspective. Bulletin of the Medical Library Association, 79(1), 1-9.

Holst, R., Funk, C. J., Adams, H. S., Bandy, M., Boss, C. M., Hill, B., Joseph, C. B., \& Lett, R. K. (2009). Vital pathways for hospital librarians: Present and future roles. Journal of the Medical Library Association, 97(4), 285292.

Jennings, M. B., \& Loan, L. A. (2001). Misconceptions among nurses about evidence-based practice. Journal of Nursing Scholarship, 33(2), 121-127.

Klem, M. L., \& Weiss, P. M. (2005). Evidence-based resources and the role of librarians in developing evidence-based practice curricula. Journal of Professional Nursing, 21(6), 380-387.

Laurence, P. R., \& Lorsch, J. W. (1986). Organization and environment: Managing differentiation and integration. Boston, MA: Harvard Business School Press.

Luzinski, C. (2011). Introducing the official leadership journal of the magnet ${ }^{\circledR}$ recognition program. Journal of Nursing Administration, 41(10), 389390.

Mitcham, C. (2005). Lyotard, Jean-Francios. In C. Mitcham (Ed.), Encyclopedia of science, technology, and ethics (Vol. 3, pp. 1145-1146). Detroit, MI: Macmillan Reference USA. 
Reavy, K., \& Tavernier, S. (2008). Nurses reclaiming ownership of their practice: Implementation of an evidence-based practice model and process. The Journal of Continuing Education in Nursing, 39(4), 166-172.

Rourke, D. R. (2007). The hospital library as a "Magnet Force" for a research and evidence-based nursing culture: A case study of two magnet hospitals in one health system. Medical Reference Services Quarterly, 26(3), 47-54.

Schein, E. H. (2010). Organizational culture and leadership (4th ed.). San Francisco, CA: Jossey-Bass.

Scott, W. R., \& Davis, G. F. (2007). Organizations and organizing: Rational, natural, and open systems perspectives. Upper Saddle River, NJ: Pearson Prentice Hall.

Simon, H. A. (1973). Organization man: Rational or self-actualizing? Public Administration Review, 33(4), 346-353.

Smith, C. S., Francovich, C., \& Gieselman, J. (2000). Pilot test of an organizational culture model in a medical setting. The Health Care Manager, 19(2), 68-77.

Starr, P. (1982). The social transformation of American medicine: The rise of a sovereign profession and the making of a vast industry. New York, NY: Basic Books.

Strickland, R. J., \& O'Leary-Kelley, C. (2009). Clinical nurse educators' perceptions of research utilization: Barriers and facilitators to change. Journal for Nurses in Staff Development, 25(6), 164-171.

Thibodeau, P. L., \& Funk, C. J. (2009). Trends in hospital librarianship and hospital library services: 1989-2006. Journal of the Medical Library Association, 97(4), 273-279. doi:10.3163/1536-5050.97.4.011

Thompson, G. N., Estabrooks, C. A., \& Degner, L. F. (2006). Clarifying the concepts in knowledge transfer: a literature review. Journal of Advanced Nursing, 53(6), 691-701.

Torpy, J. M, Lynm, C, \& Glass, R. M. (2009). Evidence-based medicine. JAMA, 301(8), 900. 
Weick, K. E., Sutcliffe, K. M., \& Obstfeld, D. (2005). Organizing and the process of sensemaking. Organization Science, 16(4), 409-421.

Wolfgram, P. A. (1985). Hospital libraries in the United States: Historical antecedents. Bulletin of the Medical Library Association, 73(1), 32-38. 